\title{
Psychological consequences of post-traumatic stress disorder in post-conflict situations
}

\author{
Zarema Masaeva ${ }^{1, *}$, Laura Kagermazova ${ }^{2}$ \\ ${ }^{1}$ Chechen state University, 364093 Grozny, Russia \\ ${ }^{2}$ Chechen state pedagogical University, 364031 Grozny, Russia
}

\begin{abstract}
. this paper presents a scientific and theoretical study of the psychological consequences of post-traumatic stress disorder in a postconflict region. These circumstances cause active attention to the region, where two military campaigns took place and for a long time residents of the Chechen Republic were under negative influences that affected their psychological state, causing symptoms of post-traumatic stress disorder. All these points require an active study of this issue, as at present there are residual effects of post-traumatic stress disorder in persons who have survived military conflicts. To resolve the psychological consequences it is necessary to increase psychological stability and mental security providing psychological security of the surrounding space.Various studies of PTSD symptoms have shown that the following psychological consequences are mainly observed: obsessive memories, repeated internal living of a negative traumatic situation, nightmares, stress, overstrain, accelerated physiological reactions, apathy. All the negative aspects of the manifestation of PTSD require the organization of psychological correction in the first place the psychological diagnosis using effective tools with which you can get objective comprehensive and reliable results.
\end{abstract}

\section{Introduction}

In the conditions of global changes, there is an understanding of the importance of studying the psychotraumatic impact of military actions on people who have undergone hostilities, representing a particularly urgent problem, manifestations of stress disorders, against which mental disorders are manifested, which is the main internal obstacle in the process of psychological adaptation to a peaceful environment. In the situation of returning to peaceful life, new psychological problems in the form of various stress and mental disorders associated with social maladaptation begin to layer on the previously existing problems. There are many examples of detection of borderline neuropsychiatric disorders in persons subjected to military action. Those who have been in military conflicts, both in the long and short term, need special attention.

Today, there is a need to pay close attention to this problem in one of the regions of the Russian Federation, in which two military campaigns took place, which led to a variety of psychological problems of both combatants and civilians. Military campaigns have been

\footnotetext{
*Corresponding author: masaeva-2009@mail.ru
} 
completed for a long time, but the problem of the psychological aspect of the psychological protection of people remains open for study and consideration in the scientific and psychological plan in order to explore the essential problem points to offer solutions to the difficulties encountered. This circumstance shows both in theoretical and practical aspects there is a need for scientific and psychological research to create a psychologically comfortable and safe environment in all spheres of life.

Many representatives of the scientific world of psychology study of the psychological consequences of military conflict: A. B. Dovgopolyuk, A. G. Maklakov, G. N. Timchenko, N. In. Tarabrina, V. S. Litvintsev, A. G. Karani, B. V. Kolodin, H. B. Akhmedov, G. A. Fastiv sewers, A. B. Akhmedov, I. S. Chuguev, V. G. Vasilevsky, A. B., Dovgopolyuk, G. A. Rostovtsev, C. R. Brewin, K. D. Tatt and Janice, T. B. Dmitrieva, E. M. Epanchintseva, E. V. Snetkov, A. N. Kharitonov, I. B. Ushakov, and others [10].

The study of the consequences of PTSD is becoming quite popular not only in medicine, but also in the socio-psychological aspect, which is associated with the increasing dynamics and pronounced psychological consequences of armed actions [2].

The issue of the settlement of military conflicts carries not only a political, but also a psychological basis, because any emergency situation does not pass without consequences. These manifestations of the psychological plan for a long time accompany people even in the absence of conflict situations, peaceful life, creating many difficulties that require attention to solve. All this makes it necessary to study the psychological characteristics of the manifestation of PTSD in persons who witnessed military conflicts to ensure a safe space and promote health, after prolonged exposure to military situations, actively affecting the traumatic effect on the psyche. There is a main feature of PTSD which consists in manifestation at the persons who were in military conditions unexpectedly through long time in the conditions of General well-being in activity [3].

\section{Sample description}

After the end of hostilities for several years, studies were conducted among the population of the Chechen Republic to identify the effects of PTSD.

In the conducted psychological researches author's questionnaires, psychodiagnostic techniques and supervision were applied.

A comprehensive socio-psychological analysis in the Chechen Republic showed that for thirteen years the region was in a state of high mental tension and inadequate living conditions. All this suggests that the inhabitants of the Republic for a long time were under the influence of negative social and psychological factors that contributed to the manifestation of mental health abnormalities. The psychological consequences of PTSD depend on the quantitative and qualitative component of stress disorders, after the end of military conflicts.

Population studies in various countries show that manifestations of PTSD are observed among the population living in areas of military situations, which indicates a high strength of the pathogenic influence of emergency circumstances on the psychological state of the individual. In this situation, the civilian population is in a double-digit position, unlike the military, the civilian population has no experience of resistance and resistance to military situations, as well as skills and abilities for survival and self-defense. Awareness of these positions in personal helplessness and an increased level of anxiety about what is happening for yourself, family and friends, reduces personal resistance to stress and increases the possibility of manifestation of PTSD. However, not all survivors of psychological disorders develop PTSD in the presence of its individual signs. 
According to the research (H. B. Akhmedova, K. A. Idrissov) half of the population was able to cope with mental influence using internal adaptive capabilities or timely psychological support [4].

Experienced tragic reactions with the probable unity of some manifestations in the context of secondary manifestations of memories of negative events, can not be defined to PTSD, as there are no obvious personal transformation of security at this stage of social relations with society.

Nevertheless, the question of the development of PTSD in some situations and its absence in another situation remains open, despite countless large-scale studies on this issue $[2,5,6]$.

The indicator level of education is a very significant factor in the formation of PTSD. The development of PTSD is affected by the family state, the presence of accentuation, the burden of mental trauma, a weak level of stress resistance, a tendency to antisocial behavior. The presence of mental trauma in childhood can be a factor in the development of PTSD in emergency military conditions.

An emergency is a necessary but insufficient indicator for the development of PTSD, as it depends on the type of higher nervous activity. Dissociative experiences of the individual at the stage of traumatic experience affect the development of PTSD.

Constant individual psychological personality traits and transient psychophysiological States contribute to the formation of affective reactions in circumstances of life risks. In dysfunctional situations, short-term affective reactions can lead to serious mental abnormalities found in PTSD.

On the basis of the conducted researches K. A. Idrisov, V. N. Krasnov showed that the prevalence of mental disorders among the population of the Chechen Republic was at the level of $86 \%$ - in 2002 and $75 \%$ - in 2004. a sufficiently high degree of prevalence of PTSD was also Revealed - above $30 \%[1,7,8]$.

In 2011 , a study by K. A. Idrissov, has shown that a phased research the psychological effects of persons in armed conflict is gradually reduced, but still remains higher in comparison with regions where military conflicts arose. More intensive dynamics of PTSD was observed in the first years, then the positive dynamics stopped, which may be the fact of the transition of PTSD to chronic forms of manifestations.

Some studies present the impact of genetic factors on the formation of PTSD: avoidance symptom, physiological reactivity, stable genetic components, twins. Features of temperament form a true indicator of predicting the formation of PTSD. The set of psychodynamic factors of threats of occurrence of PTSD is investigated in the scientific world least of all. There is a small amount of scientific research related to this factor. According to scientific research in Korea, introverts are most susceptible to PTSD in the conditions of military operations. It was also found that biological and psychodynamic factors have high predictability in comparison with individual psychological and social environmental factors $[9,10]$.

The manifestation of the prerequisites begins to manifest itself at the beginning at the stage of mental overstrain of emotional and volitional stability, which begins to contribute to the violation of adaptive stability and the manifestation of neurotic symptoms.

Many scientific studies have been conducted to identify psychological problems caused by the effects of PTSD during and after armed conflicts. Researchers who studied the effects of PTSD in the Chechen Republic (Idrissov K. A.. H. B. Akhmedov) identified a number of psychological consequences of PTSD: obsessive memories, internally living a negative traumatic situation repeatedly, nightmares, stress, overstrain, accelerated physiological reactions (heartbeat, rapid breathing, sweating, nausea, muscle overstrain, avoidance (places, thoughts, sensations), apathy, loss of interest in life, emotional exaltation, lack of representation of the future, insomnia, anxiety, outbursts of anger, 
aggression, irritability, difficulty concentrating and staying focused, increased excitability, etc.

\section{Discussion of results}

On the basis of a number of observations of domestic scientists, it is possible to determine typical circumstances that have a significant impact on the development of PTSD in military local conflicts: the expectation of a difficult situation, false media information, relatives, the duration of the military conflict, the personal type of response. One of the difficult periods spent in areas of military action is the change in self-esteem, euphoria, etc.

The most often subject to PTSD in conditions of military conflict are rescuers, doctors, journalists, civilians. The psychological consequences of PTSD are particularly vulnerable. Among which there is a huge set of the problem positions demanding to itself close attention for the purpose of rendering psychological support [9].

The negative psychological consequences of PTSD include: psychopathization of personality, difficult maladaptation, the emergence of repeated depression, the emergence of fears, panic, fear of the dark, various psychological dependencies (alcohol, drug addiction, etc.), abnormal behavior [7].

All the above-mentioned psychological consequences after the war with the appearance of PTSD need the organization of psychological correction and support for persons suffering from PTSD symptoms. To ensure positive dynamics during psychological correction, it is necessary to conduct psychological diagnostics aimed at a comprehensive study of the existing problems in persons suffering from PTSD symptoms using the appropriate target value of diagnostic tools, in which the detected results are reliable and reliable. When determining the methods, it is important to take into account the specific characteristics of the persons with whom the diagnosis will be carried out to ensure full coverage of situational moments that may affect the final diagnostic results [1].

Within the framework of psychological correction of PTSD, the process of personal growth is very effective for self-improvement of a person. Systematic self-development of existing personal potentials is reflected as a complex characteristic of personal and psychological characteristics. This position is to determine the internal guidelines, the preservation and permanence of the activities of external environmental factors [2].

The indicators of personal potential include: independence, autonomy, meaningfulness, stability, readiness for internal transformations, time perspective. These indicators are important for the formation of persons who have suffered psychological trauma of post-war events, as they develop personality traits that give him the opportunity to recover independently after severe events of a psychological nature. First of all, the personality provides overcoming of various phobias, fears. In the process of psychological correction of personality, the following psychological technologies can be used: philosophical and anthropological concept of E. Fromm, existential Gestalt-therapeutic approach of F. S. Perls, client-centered approach of K. R. Rogers, transpersonal psychology, etc. [5].

It is necessary to organize psychological correctional work on the basis of three interrelated organizational stages: diagnostic, correctional and prognostic.

After the end of hostilities in the Chechen Republic, a lot of work was done to provide psychological assistance to the residents of the Republic to remove the negative psychological consequences, realizing that each person is individual and has its own characteristics that are not inherent in others, as well as individual internal resources that make it possible to cope with negative impacts. Given the internal potentials and capabilities of the individual, we can say that some residents need psychological support to remove negative psychological indicators, which in turn affect the life of the individual, creating barriers and obstacles in overcoming these consequences. 
Realizing that PTSD is characterized by a delayed reaction, characterized by the manifestation of various symptoms over a long period of time, it is important today to pay attention to the contingent in need of psychological support.

Many studies have described the effects of PTSD in past hostilities as the effects of long-term delayed manifestation. In the post-conflict region there are manifestations of the consequences of psychological trauma in the context of the effect of post-conflict, as residual phenomena manifested in various forms in persons who have suffered mental trauma.

Previous studies have found that in the absence of timely psychological assistance spontaneous healing occurs only in small quantities, and mostly PTSD acquires the character of similar symptoms of somatic disorders.

Conclusion

Residents living in the area previously covered by the territory of military conflicts develop an increased rate of PTSD, which are stored for a long time, increasing the threat of formation of various mental and somatic disorders, plunging to the violation of adaptation to changing environmental circumstances and significantly reducing the wellbeing of the victims. The need to provide mobile for a short time, taking into account the individual and age characteristics of social and psychological assistance to victims causes the search for effective and modern technologies and approaches with the involvement of professional assistance of psychologists.

\section{References}

1.D. Shek, Family Therapy. 34(2), (2007)

2.O.B. Esina Ural medical journal. 8 (141), 38-42 (2016)

3.O.V. Zadarinsky, Social work: theories, methods, and practice. 1 (5), 24-33 (2016)

4.K. Idrisov, Annual final conference of the faculty of ChSU ser. "Natural Sciences" Diagnosis and therapy of adaptation disorder at the remote stage of a long-term emergency. 89-92 (2016)

5.A.G. Karayani, Yu.M. Karayani, Psychological assistance to military personnel in a combat situation (Moscow, 2016)

6.Z.V. Masaeva? Problems of modern pedagogical education. 52-7, 586-593 (2016)

7.I.V. Abakumova, O.V. Telnova, Collection of materials of the II all-Russian Congress of psychologists of power structures of the Russian Federation Mechanisms of psychological protection as factors hindering the development of PTSD in combatants, 356364 (2016)

8.Z.V. Masaeva, L.TS. Kagermazova, Humanities. 4 (40), 122-126 (2017)

9. M.M. Reshetnikov, Mental trauma (2017)

10. O. O. Adesope, T. Lavin, T. Thompson, C. Ungerleider, Review of Educational Research, 80(2), 207-245 (2010) 